\title{
Análise das causas de acidentes de trabalho ocor- ridos numa obra e possíveis relações com Projeto
}

Priscilla Elisa de Azevedo Basto

Escola Politécnica de Pernambuco

Universidade de Pernambuco

50.720-001 - Recife, Brasil

priscilalsht@ poli.br

\author{
Prof. ${ }^{a}$ M.Sc. Bianca $M^{\text {a }}$ Vasconce- \\ los \\ Escola Politécnica de Pernambuco \\ Universidade de Pernambuco \\ 50.720-001 - Recife, Brasil \\ biancalsht@poli.br
}

\author{
Prof. ${ }^{\circ}$ Dr. Béda Barkokébas Jr. \\ Escola Politécnica de Pernambuco \\ Universidade de Pernambuco \\ 50.720-001 - Recife, Brasil \\ bedalsht@ poli.br
}

\begin{abstract}
Resumo Analisar os acidentes de trabalho ocorridos num canteiro de obra de grande porte, de modo a verificar possíveis vínculos com a etapa projetual e como poderia ter sido evitado, com ênfase nos Projetos de Arquitetura e Estrutura. O estudo consistiu inicialmente na coleta de dados de acidentes, através Fichas de Análise de Acidentes do Trabalho - FAAT, ocorridos num canteiro de obras de grande porte, localizado na cidade do Recife. Em seguida, foi realizada uma análise dos 367 acidentes ocorridos no período outubro de 2010 e março de 2012, com a utilização do Método de Análise de Vínculo entre o Acidente e o Projeto - MAVAP (Vasconcelos, 2012. Este consiste na estruturação de planilhas contendo as informações gerais e analíticas de cada acidente de trabalho. Através desta análise, identificou-se os acidentes de trabalho que poderiam ser evitados pela inserção das considerações de segurança do trabalho no Projeto, além da identificação dos fatores causais predominantes para a ocorrência dos acidentes analisados, das medidas preventivas que poderiam ter sido adotadas e dos tipos de projeto vinculados, com ênfase nos projetos de Arquitetura e Estrutura. Enfim, a pesquisa evidenciou, a existência de acidentes que poderiam ter sido evitados através da inserção de medidas preventivas adotadas na fase projetual. Além disso, constatou-se que a conscientização/formação dos profissionais responsáveis pelo projeto do empreendimento e a disponibilização de materiais de auxílio, como softwares que recomendem diretrizes a serem seguidas em cada etapa e tipo de projeto, têm papel fundamental na Prevenção de acidentes através da elaboração de Projetos - Pap.
\end{abstract}

Palavras-Chave: Análise de acidentes. Prevenção através de Projeto. Segurança do trabalho 


\section{Introdução}

O setor da construção civil se destaca no campo da segurança do trabalho, já que apresenta uma grande diversidade de riscos. Segundo Vasconcelos (2009), em seu processo produtivo, a indústria desse setor, envolve vários profissionais habilitados, tendo cada um deles responsabilidade parcial sobre o empreendimento. Gehbauer (2004), numa visão ampla do processo construtivo destaca os seguintes agentes: investidores, engenheiros, arquitetos, organizações executoras, fornecedores de materiais e clientes.

Como o projeto arquitetônico é o ponto de partida para os demais projetos técnicos e para aqueles elaborados para a produção, o arquiteto e os demais projetistas, devem ter em vista, como serão realizados os serviços e como será a interação entre o homem (que executa o serviço) e a edificação (VASCONCELOS, 2009).

A Directiva Européia $n^{\circ}$ 92/57/CEE aponta que as escolhas arquitetônicas inadequadas ou o planejamento incorreto dos trabalhos durante a elaboração do projeto do canteiro de obras, contribuíram para mais da metade dos acidentes de trabalho em canteiros da União Européia.

Da mesma forma, um estudo com a análise de 450 acidentes de trabalho causadores de mortes ou ferimentos ao trabalhador de diversos seguimentos da indústria da construção civil, fornecidos pela Occupational Safety and Health Administration - OSHA e pelo programa Fatality Assessment and Control Evaluation - FACE do National Institute of Occupational Safety \& Health - NIOSH, ambas instituições dos Estados Unidos, realizada por Behm (2006), mostrou que $30,2 \%$ (136) desses acidentes possuíam vínculo com o projeto, em que caso medidas preventivas tivessem sido adotadas na fase de projeto poderiam ter evitado os acidentes. Essa análise demonstra o quanto é importante que a segurança do colaborador da obra esteja em foco desde os primeiros passos do projeto.

A Prevenção de acidentes através da elaboração do Projeto (PaP) ou Prevention through Design (PtD), como é conhecido no ambiente internacional, é definido pela NIOSH (2012) como o direcionamento de segurança e saúde do trabalho necessária no processo de projeto para prevenir ou minimizar os perigos relacionados ao trabalho e riscos associados à construção, fabricação, uso, manutenção e arrumação de instalações, materiais e equipamentos. Devido à necessidade da introdução desse conceito foram criados em diversos lugares do mundo regulamentos e diretivas que exigem um comprometimento dos projetistas para com a segurança do trabalhador, causando a posterior diminuição dos acidentes e trazendo os diversos benefícios a ela atrelados.

\section{Objetivo}

Analisar os acidentes de trabalho ocorridos num canteiro de obra de grande porte, de modo a verificar possíveis vínculos com a etapa projetual e como poderia ter sido evitado, com ênfase nos Projetos de Arquitetura e Estrutura.

\section{Estado da arte}

O alto índice de acidentes no setor da construção foi evidenciado pela Agência Européia para a segurança e a Saúde no Trabalho (2003) que afirma que em nível mundial os trabalhadores da construção tem três vezes mais probabilidade de sofrer ferimentos que os trabalhadores de outras áreas. A partir dos fatores peculiares da indústria da construção civil, como o tamanho das empresas, a curta duração das obras, as constantes transformações da obra e a rotatividade da mão de obra, percebe-se que estes acabam por influenciar principalmente na formação/conscientização dos trabalhadores. Para que haja uma redução do número de acidentes é necessária a presença da Segurança e Saúde do Trabalho - SST como forma de evitar eventos indesejados, sejam eles acidentes ou incidentes, originados a partir de riscos presentes no ambiente de trabalho.

Além da inserção da SST dentro do canteiro de obra, sua presença também é necessária na fase conceitual da obra, tendo em vista que um projeto bem concebido poderá evitar improvisações futuras, constatadas muitas vezes, após a ocorrência de acidentes. Logo, quando as preocupações com os riscos surgem desde a fase de projeto, existe uma prevenção de riscos mais efetiva. Para isso, deve-se intervir no processo de elaboração de projetos, de modo que medidas de segurança sejam inseridas para garantir a saúde do trabalhador.

\subsection{Elaboração de projetos}

A fase conceitual ou de concepção esta presente no início do ciclo de vida do empreendimento, sendo seguido pelas fases de execução, uso, manutenção e desconstrução. De acordo com Vasconcelos (2009) é nesta fase em que são executados os projetos e o planejamento da obra, realizando estimativa da sua viabilidade e potencial de sucesso.

Segundo o Manual de Escopo de Serviços de Coordenação de Projetos (AGESC, 2007b), a fase de concepção visa apoiar o empreendedor no levantamento e determinação do conjunto de dados e de informações que pretende conceituar e caracterizar o produto e as suas restrições. 
Além de um projeto que retrate o produto, é aconselhável que seja feito um projeto para produção deste, onde serão definidos os procedimentos e sequências de trabalho, recursos e componentes necessários para a sua construção, ajudando a diminuir os riscos, pois diminui a

probabilidade da realização de improvisos para resolver problemas com especificações e detalhamentos incompletos, falhos ou incompatíveis (FABRÍCIO, 2004).

Oliveira (2004) demonstra a importância do projeto de uma edificação através da sua determinante influência sobre o desempenho desta, pois ele permite a definição adequada da produção ainda na fase de concepção do produto.

Desse modo pode ser observado, que na fase de concepção são tomadas decisões que podem otimizar o produto tanto do ponto de vista financeiro, do desempenho de uma edificação em seu uso e dos processos produtivos. Portanto é necessária a integração entre a atividade de projeto e da construção e uma eficaz coordenação dos projetos.

O projeto final de um empreendimento é formado a partir da união de vários projetos, em que a coordenação de projeto deve orientar quanto a compatibilização destes. Vasconcelos (2012) reuniu os tipos de projetos com base nas características, objetivos e nas fases da obra, conforme mostra o Quadro 1.

\begin{tabular}{|c|c|c|}
\hline TIPOS & GRUPOS & CARACTERIZAÇÄO \\
\hline Arquitetura; Estrutura; & Projetos Base & $\begin{array}{l}\text { Projetos informativos, que fomecerão } \\
\text { suporte aos demais tipos de projetos. }\end{array}$ \\
\hline $\begin{array}{l}\text { Instalações Hidrossanitárias; } \\
\text { Instalaçōes Elétricas. }\end{array}$ & Projetos Complementares I & $\begin{array}{l}\text { Projetos que darão suporte à habitabilidade } \\
\text { e à adaptação de novos sistemas, }\end{array}$ \\
\hline $\begin{array}{l}\text { Instalações Telefônicas; } \\
\text { Instalações de Gás; Sistema de } \\
\text { Combate à Incêndio; Projeto de } \\
\text { Segurança (PCMAT); Projeto do } \\
\text { canteiro de obras. }\end{array}$ & $\begin{array}{l}\text { Projetos Complementares } \\
\text { ॥ }\end{array}$ & $\begin{array}{l}\text { Similares e subsequentes aos Projetos } \\
\text { Complementares I, fornecem suporte ao } \\
\text { funcionamento das instalações provisórias e } \\
\text { permanentes. }\end{array}$ \\
\hline $\begin{array}{l}\text { Automação predial; Ar } \\
\text { condicionado / Aquecimento; } \\
\text { Sistema de Antena; Sistema de } \\
\text { Internet. }\end{array}$ & Projetos Especiais & $\begin{array}{l}\text { Projetos de tecnologia mais recente e que } \\
\text { contribuem na habitabilidade e no conforto } \\
\text { das instalaçäes permanentes. }\end{array}$ \\
\hline $\begin{array}{l}\text { Projeto de Contenção; Projeto } \\
\text { de Escoramento; Projeto de } \\
\text { Cofragem }\end{array}$ & Projetos para produção I & $\begin{array}{l}\text { Projetos que tomam como base os projetos } \\
\text { anteriores e destinam-se a orientarem a } \\
\text { produçãa, funcionando como um }\end{array}$ \\
\hline $\begin{array}{l}\text { Projeto de Alvenaria; Projeto de } \\
\text { Esquadrias; Projeto de } \\
\text { revestimento de Fachadas. }\end{array}$ & Projetos para a produção II & procedimento de execução. \\
\hline $\begin{array}{l}\text { Projeto de Máquinas e } \\
\text { Equipamentos }\end{array}$ & Projetos Correlatos & $\begin{array}{l}\text { Projetos de máquinas e equipamentos } \\
\text { utilizados pela produção do } \\
\text { empreendimento, com potencial de atuar na } \\
\text { produtividade e na segurança no trabalho } \\
\text { da obra. }\end{array}$ \\
\hline
\end{tabular}

Para entender o vínculo existente entre os projetos apresentados no Quadro 1 e a segurança no trabalho, é essencial a compreensão de quais os seus objetivos, elementos e o processo de elaboração, pois desse modo após a identificação do acidente que poderia ser evitado através de medidas no projeto, as providencias são tomadas em cima do projeto específico em qual o risco está inserido.
Vale ressaltar que o presente trabalho foca os Projetos Base (Arquitetura/ Estrutura).

Na prática, o projeto de arquitetura serve de modelo para os demais projetos, fazendo com que influencie, na antecipação e identificação dos possíveis problemas nas etapas de execução e manutenção. A qualidade de suas informações torna-se indispensável para o sucesso do empreendimento, pois as decisões tomadas na fase de concepção podem causar prejuízos a muitas variáveis em toda vida útil do empreendimento (VASCONCELOS, 2009).

No projeto Estrutural, o projetista deve ter uma afinidade inicial com a arquitetura. Isto se deve ao fato que, a forma define a estrutura, e em consequência, a escolha dos materiais e dos processos produtivos. É o projeto arquitetônico, juntamente com o projeto das instalações, que define quais as posições e as dimensões dos elementos estruturais, de forma que estejam em harmonia com o ambiente que o cerca.

Rebello (2000) define estrutura, no caso das edificações, como um conjunto de elementos que interagem entre si para alcançar um objetivo de criar um espaço no qual pessoas exercerão diversas atividades. Estes elementos estruturais são as vigas, lajes e pilares ou o agrupamento destes elementos, que tornam-se o caminho percorrido pelas forças que atuam sobre a edificação para chegar ao solo. (REBELLO, 2000; GIONGO, 2007).

Devido a grande influencia e aos suporte dado pelos Projeto Base sobre demais projetos da obra, grande parte das considerações de segurança do trabalho são aplicáveis aos projetos de Arquitetura e de Estrutura.

\subsection{Prevenção de acidentes através da elabo- ração do projeto na Construção Civil- Pap}

A prevenção através do projeto foi sugerida primeiramente no Manual de prevenção de Acidentes do National Safety Council - NSC, em 1955 (GAMBATESE et al., 1997). Em 1985, o Internacional Labour Office - ILO percebeu a necessidade de o projetista envolver e considerar a segurança do canteiro de obras em seu trabalho (BEHM, 2005).

Atualmente, o projetista tem sido identificado, na indústria da construção, como um detentor de grande impacto na segurança do trabalho, já que a elaboração de projetos, como foi demonstrada anteriormente, é uma atividade de crescente complexidade, que exige uma visão global dos diferentes negócios envolvidos e de outras áreas da atividade (VASCONCELOS et 5 al., 2011a). Neste setor, o tempo destinado ao projeto é reduzido, acarretando em 
improvisações na obra, que somadas a ausência da introdução das considerações de SST no projeto, apresentam potencial na geração de acidentes (VASCONCELOS et al., 2011b). Logo, começar a agir considerando a segurança do trabalhador desde as fases conceituais da obra fará com que previna acidentes em diferentes partes da construção.

De acordo com Behm (2006), Pap pode ser definido como considerar a segurança no canteiro de obras na preparação dos planos e especificações para projetos de construção. Desse modo um dos principais objetivos da introdução esse conceito será prevenir ou reduzir doenças, acidentes ou mortes no trabalho através da inclusão de considerações sobre prevenção em todos os projetos que tenham impacto sobre o trabalhador (NIOSH, 2012).

Manuele (2008) aponta entre os principais benefícios obtidos pela aplicação do $\mathrm{PaP}$, o aumento da produtividade, a diminuição dos custos de operação e a significante redução dos riscos.

Isso demonstra, o quanto também pode ser lucrativo para a empresa construtora aplicar a segurança desde as fases conceituais da obra.

O gráfico apresentado por Szymberski (1997) (figura 1) evidencia que quando a segurança é levada em consideração a partir, apenas, da fase de construção uma parcela significativa da capacidade de influência na segurança do trabalhador é perdida. Pode-se constatar ainda a grande influência que a fase de projeto (conceitual) possui sobre a segurança no canteiro de obra.

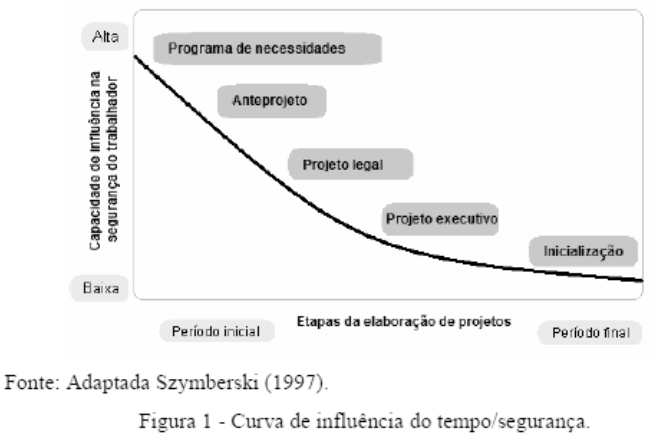

Dentre os locais engajados na Pap em seu campo normativo, pode-se citar: os Estados Unidos, a União Europeia, o Reino Unido, a Austrália e a África do Sul. Essa difusão demonstra que esse seguimento da segurança do trabalho já está sendo visado pela maioria dos continentes, havendo ainda área do PaP que foca exclusivamente o setor da Construção, conhecido a nível internacional como CHPtD - Construction Prevention through Design.
Toole e Gambatese (2008) identificaram quatro trajetórias específicas que o CHPtD pode seguir. Sendo a primeira o aumento da pré-fabricação dos elementos utilizados na construção, em seguida tem-se o aumento do uso de materiais e sistemas menos perigosos e uma maior aplicação de engenharia durante a construção. E por fim, a maior investigação e consideração espaço.

Portanto, podem-se constatar os contínuos esforços acerca de promover a segurança no 6 processo conceitual, no qual são introduzidas novas considerações regularmente, podendo-se citar como exemplo o início de pesquisas que focam a consideração da prevenção de acidentes na elaboração de projetos de construções verdes.

\subsection{Análise das causas de acidentes}

Um acidente pode estar vinculado a diferentes causas que estão inter-relacionadas e em constante transformação, ou seja, o acidente é multicausal. Em virtude dessa multiplicidade e diversidade de fatores envolvidos, é essencial o conhecimento de todos os possíveis fatores de riscos no ambiente de trabalho.

Para evitar a ocorrência de eventos indesejados ou, ainda, diminuir seus impactos danosos, há a necessidade de investigar exaustivamente todas as possibilidades destes, para conhecer suas causas e efeitos e, em seguida, estabelecer os instrumentos eficazes de sua prevenção e controle (BARBOSA FILHO, 2001).

De acordo com Almeida, a análise de acidentes está ganhando mais espaço como ferramenta auxiliar na prevenção de acidentes, dada a importância do conhecimento dos fatores causais desses eventos para a sua efetiva prevenção, estando presente no gerenciamento de riscos. Atualmente existem vários métodos criados com essa finalidade. A escolha deste pode ser limitada por diversos fatores, como o tipo de indústria a qual a investigação está destinada ou o setor que necessita desses dados (engenharia de segurança do trabalho, qualidade, meio ambiente, etc) (MAIA, 2008).

A OHSAS-18001 (2007) aponta que a organização deve estabelecer, implementar e manter procedimento(s) para registrar, investigar e analisar incidentes com as finalidades de identificar a necessidade de ações corretivas e a oportunidade de ações preventivas.

No Brasil o órgão governamental responsável pela análise de acidentes é o Ministério do Trabalho e do Emprego (MTE) que constatou que a maioria das empresas, através de analises interna, não identifica os reais fatores ligados ao acidente, atribuindo como culpa deste a falha humana. Não eliminando o perigo que pode vir a causar novos acidentes. 
Diversas áreas podem ser beneficiadas pela correta avaliação das causas do acidente, pois estará diminuindo os custos econômicos e sociais, além de eliminar o risco, o que estará prevenindo a ocorrência de um novo evento adverso.

De acordo com o MTE (2010) é necessária uma metodologia estruturada para coleta, organização e análise das informações para que uma investigação seja eficaz. Com base nas etapas apontadas pelo MTE (2010) elaborou-se a figura 2 .

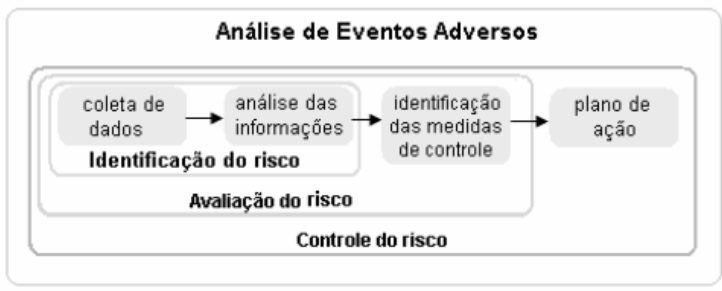

Figura 2 - Etapas da análise de eventos adversos.

Esta análise, através dos seus diversos métodos, é de imensa importância na identificação do 7 vínculo entre o evento e o projeto, apontando qual a origem do risco e o fator causal que agiu predominantemente na ocorrência do acidente, de modo que o projetista possa tomar providências para contribuir na eliminação/redução dos riscos de acidente.

\section{Metodologia}

Primeiramente foi realizada uma revisão bibliográfica em livros, artigos publicados em revistas periódicas, artigos publicados em congressos, dissertações de mestrado, normas nacionais e internacionais.

Para tanto, a pesquisa foi subdividida nos seguintes temas:

- Segurança no Trabalho: revisão dos conceitos básicos sobre acidentes e incidentes de trabalho, perigo e riscos e SST na Construção Civil;

- Elaboração de Projetos: etapas do processo de elaboração de projetos, enfatizando os projetos de arquitetura e estrutura;

- Prevenção através do Projeto: estudou-se o tema a partir de publicações internacionais, que explicam como esse tipo de prevenção pode ser aplicada, qual a sua importância e como está sendo constatada a sua utilização em diferentes países;
- Análise de acidentes: foi feita uma pesquisa para conhecer as vantagens e os métodos utilizados como ferramenta de prevenção e controle dos acidentes de trabalho.

Também foram realizadas pesquisas sobre os diversos tópicos em sites de órgãos governamentais internacionais como a National Institute of Occupational Safety \& Health - NIOSH, a Occupational Safety and Health Administration - OSHA e a Organização Internacionaldo trabalho OIT, e uma pesquisa documental, com foco em normas de elaboração de projetos, para o conhecimento das etapas dos projetos de arquitetura e estrutura.

Em atividade paralela foi realizado um estudo de caso, com coleta e análise de casos de acidentes de trabalho ocorridos, no período compreendido entre outubro de 2010 e março de 2012, em um canteiro de obras localizado na Região Metropolitana do Recife.

Esta obra possui previsão de entrega novembro de 2012 e terá uma área total construída de $286.000 \mathrm{~m}^{2}$. Além disso, o empreendimento possui uma média de 4.333 funcionários realizando atividades diariamente através de empregos diretos e indiretos.

O estudo consistiu inicialmente na coleta de dados de acidentes, ocorridos no canteiro descrito anteriormente, através Fichas de Análise de Acidentes do Trabalho FAAT. Foram utilizados modelos com diferente estruturação, mas que possuíam uma compatibilidade de informações necessárias para realização da análise.

A análise do acidente foi realizada a partir do Método de Análise de Vínculo entre o Acidente e o Projeto - MAVAP (Vasconcelos, 2012), que consiste inicialmente na estruturação uma planilha contendo as informações gerais de cada acidente de trabalho contidos nas FAAts coletadas.

Esta planilha de informações gerais abrange os seguintes dados: a referenciação do acidente, o país e a localidade de onde ele aconteceu, a função do colaborador acidentado, o setor da obra onde o acidente ocorreu, a gravidade do acidente, classificando o evento em acidente com lesão leve (no qual o colaborador não foi afastado do canteiro após a ocorrência deste), acidente com lesão grave (no qual o mesmo foi afastado do canteiro por um determinado período de tempo, destinado a recuperação da lesão) ou fatal, e por fim a descrição das causas 8 do acidente - narrativa que esclareça as ações, objetos ou ambiente responsável predominantemente pela sucessão do acidente. Estas são informações necessárias para o reconhecimento da possível relação entre a causa do acidente de trabalho com aspectos projetuais. 
Após o preenchimento das informações gerais foi iniciada a análise de cada acidente baseada na compreensão da descrição da ocorrência, formando a planilha dedicada às informações analíticas.

Dentro desta são preenchidos, de acordo com a avaliação do evento, os campos relativos ao fator causal predominante, as providências que poderiam ter sido tomadas para que $\mathrm{o}$ acidente não volte a ocorrer, gerando a prevenção de acidentes, se o projeto poderia ter colaborado para evitar o acidente, e no caso desta última informação ser positiva, discrimina-se em que tipo de projeto poderia ter sido feito alguma modificação para evitar o acidente.

Podem ser constatados diversos fatores predominantemente causadores de acidentes. Neste trabalho serão destacados os fatores organizacionais, que acontecem devido a deficiências na organização, tanto por parte de problemas no Layout, quanto por procedimentos inadequados ou que não estão sendo executados continuamente; os fatores humanos, quando o acidente foi causado devido a uma falha humana, cuja origem pode residir em falta de conhecimento ou experiência, stress, não cumprimento de normas, distrações, dentre outros; e por fim, os fatores materiais, onde $\mathrm{o}$ acidente deve-se a defeitos em materiais, máquinas e ferramentas.

Ao fim foram obtidos os dados referentes a quantificação dos acidentes quanto a sua gravidade, a quantidade de acidentes que poderiam ter sido evitados pelo projeto, a quantificação dos fatores causais predominantes dos acidentes evitáveis através do projeto e quais os principais tipos de projeto vinculados a estes acidentes.

\section{Resultados}

Foram analisados 367 acidentes de trabalho através do Método de Análise de Vínculo entre o Acidente e o Projeto - MAVAP ocorridos na obra estudada.

Do total de acidentes analisados 345 referem-se a acidentes com lesão leve, representando $94,0 \%$ e 22 com lesões graves, representando $6,0 \%$, não havendo, portanto, nenhum acidente fatal, conforme mostra o gráfico 1 .

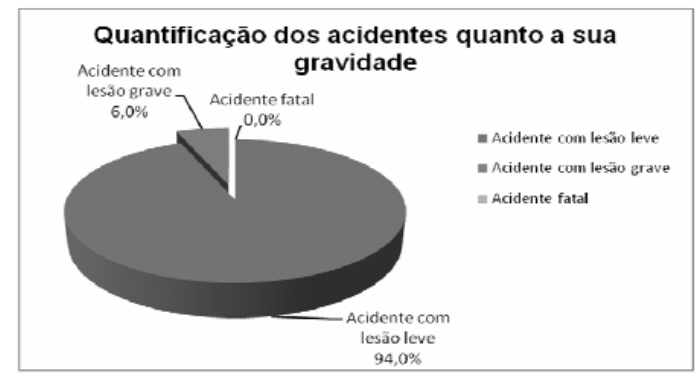

Gráfico 1 - Quantificação dos acidentes analisados quanto a sua gravidade

Os baixos números de acidentes analisados, se comparados aos parâmetros de período de tempo estudado, número de funcionários no canteiro de obras e a extensão do terreno no qual a obra se encontra, demonstram que há uma aplicação de uma política de prevenção de acidentes pela gestão empreendedora da obra, em que a grande parte dos acidentes constatados resultou em lesões reparáveis e não incapacitantes no trabalhador.

Num segundo momento, referente as informações analíticas, foram eliminados $16,0 \%$ (59 acidentes) dos acidentes totais, devido a não compreensão do acidente ou a informações insuficientes para uma análise efetiva.

Portanto, dos 308 acidentes analisados, após a anterior eliminação, nos quais foram preenchidas as informações analíticas, foi constatado que em apenas 15 acidentes deste canteiro referem-se as considerações tomadas no projeto poderiam ter evitado o acidente, representando $4,1 \%$, como demonstrado através do gráfico 2 .

Esse dado demonstra que os acidentes com lesões leves possuem pouco vínculo com o projeto, em contraposição ao apresentado no estado da arte, em que alguns dados estatísticos mostram um maior vínculo entre os acidentes com lesão grave e o Projeto.

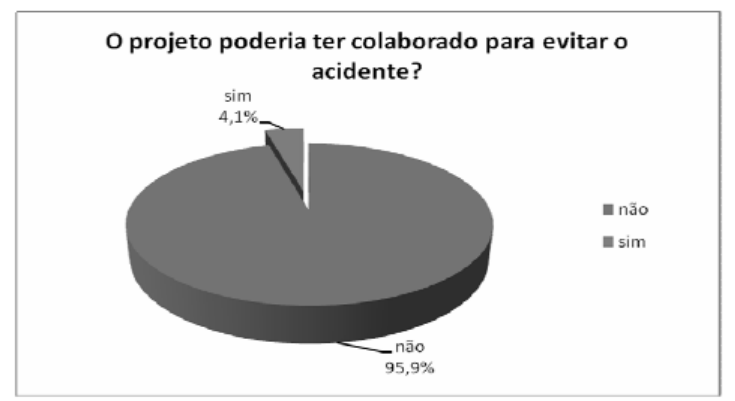

Gráfico 2 - Se o projeto poderia ter colaborado para evitar o acidente analisado.

Quanto ao fator causador predominante do acidente identificado através do projeto, que representa $4,1 \%$ dos acidentes analisados, foi constatado que aquele que contribuiu em maior número para ocorrência de acidentes foi o 
Fator Organizacional, com 13 acidentes na obra estudada, representando 86,7\%, seguido pelo Fator Material com 02 acidentes, representando $13,3 \%$, e nenhum acidente com Fator Humano como fator predominante para a ocorrência do acidente, como pode ser verificado no gráfico 3 .

Logo, pode ser constatado que a gestão empresarial é o elemento que possui maior influência na prevenção de acidentes através de projetos, por isso é necessário um comprometimento cada vez maior do projetista em procurar projetar pensando na execução da atividade, na disposição dos elementos e nos componentes inseridos dentro do canteiro de obras.

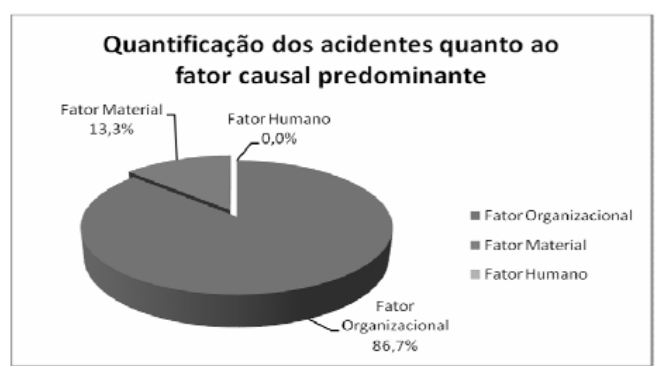

Gráfico 3 - Quantificação dos acidentes estudados quanto ao fator causal predominante.

Avaliando-se qual o tipo de projeto em que poderia ter sido realizada mudanças que evitariam os acidentes analisados, foi verificado que em mais da metade dos casos, 66 , $7 \%$ (10 acidentes), estão ligados ao Projeto de Canteiro de Obras, acompanhado pelos $26,7 \%$ (04 acidentes) vinculados ao Projeto de Segurança (ambos inclusos dentro dos Projetos Complementares II) e 6,7\% (02 acidentes) dos Projetos de Máquina, portanto dentre os demais projetos agrupados no Quadro 3.1 não foi encontrada nenhuma ligação com os acidentes, isso está demonstrado no gráfico 4.

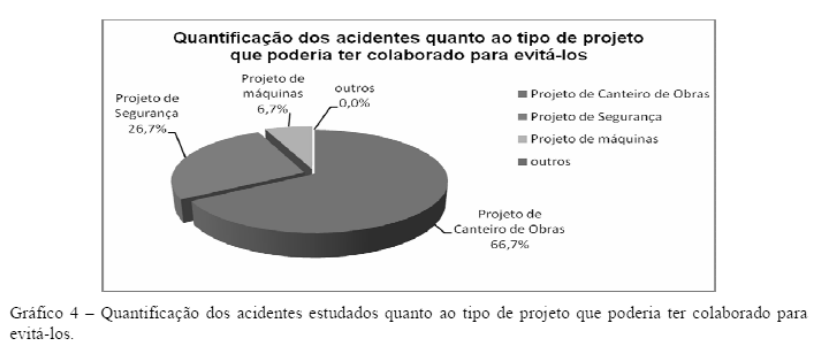

Com esses resultados, foi constado que a disposição, a delimitação e a sinalização de áreas do canteiro de obras são de imensa importância na prevenção de acidentes vinculados ao projeto. Pois, o mau dimensionamento de áreas de atividades, de vivência, armazenamento de materiais, de máquinas e de equipamentos, além da não adequação dos meios de acesso a outros níveis, como a rampa, aos trabalhos executados sobre ele ou a instalações incorreta pode contribuir para o acontecimento de diferentes tipos eventos não desejados, que podem levar a acontecer até mesmo acidentes graves.

\section{Conclusões}

O estudo apresentado neste trabalho é inovador devido a escassez de pesquisas na área de Prevenção de acidentes através da elaboração de Projetos, inclusive no Brasil, tendo que recorrer a estudos desenvolvidos em publicações internacionais para sua fundamentação.

Através da analise dos acidentes do canteiro de obras estudado, pôde-se identificar, qualificar 11 e quantificar as causas desses eventos, e consequentemente os riscos de acidentes associados. Com isso, medidas preventivas foram identificadas a fim de eliminar/reduzir a possibilidade de repetição de novos eventos.

A aplicação do Método de Análise de Vínculo entre o Acidente e o Projeto-MAVAP foi eficaz por permitir que, a identificação dos vínculos entre as causas dos acidentes e o Projeto do empreendimento estudado e do tipo de Projeto (Arquitetura/Estrutura) que poderia atuar na prevenção do acidente analisado, fossem alcançados.

O estudo obteve em seus resultados evidências de vínculos existentes entre o Projeto e os acidentes, mostrando ao meio produtivo, a existência de acidentes evitáveis através de medidas tomadas no projeto.

Por fim, pôde-se constatar que a conscientização/formação dos profissionais responsáveis pelo projeto do empreendimento e a disponibilização de materiais de auxílio, como softwares que recomendem diretrizes a serem seguidas em cada etapa e tipo de projeto, têm papel fundamental na Pap, visto que, muitos acidentes ligados ao projeto tiveram como causa predominante o Fator Organizacional, devido à deficiência no conhecimento da Pap e da escassez de materiais didáticos de auxílio ao projetista.

\section{Referências}

[1] AGÊNCIA EUROPEIA PARA A SEGURANÇA E A SAÚDE NO TRABALHO - OSHA/EU. ESTATÍSTICAS. Disponível em: <http://osha.europa.eu/pt/statistics/>. Acesso em: 20 jun. 2009.

[2] ASSOCIAÇÃO DOS GESTORES E COORDENADORES DE PROJETO. Manual de Escopo de Serviços para Coordenação de Projetos Indústria Imobiliária. São Paulo: AGESC, 2007. Disponível em: $<$ http://www.manuaisdeescopo.com.br/>. Acesso em: 18 jul. 2012. 
[3] BARBOSA FILHO, A. N. Segurança do trabalho \& gestão ambiental. São Paulo: Atlas, 2001.

[4] BEHM, M. Linking construction facilities to the design for construction safety concept. Safety Science, n. 43, p. 589-611, 2005.

[5] An Analysis of Construction Accidents from a Design Perspective. The Center to Protect Workers' Rights, January 2006.

[6] FABRÍCIO, M. O processo de projeto na construção de edifícios - Notas de Aula 2. São Carlos: Escola de Engenharia de São Carlos - Universidade de São Paulo, 2004.

[7] GAMBATESE, J. A.; HINZE, J. W.; HAAS, C. T. Tool to Design for Construction Worker Safety. Journal of Architectural Engineering, v. 3, n. 1, p. 33-41, March 1997.

[8] GEHBAUER, F. Racionalização na construção civil: como melhorar processos de produção e de gestão. Recife: SENAI, SEBRAE, GTZ, 2004.

[9] MAIA, D. C. Análise de acidentes fatais na indústria da construção civil do estado de Pernambuco. 2008. 122 p. Dissertação (Mestrado em engenharia civil) - Universidade Católica de Pernambuco, Recife, 2008.

[10] MANUELE, F. A. Prevention through Design (PtD): History and Future. Journal of Safety Research, n. 39, p.127-130, 2008.

[11] MINISTÉRIO DO TRABALHO E EMPREGO. Guia de análise acidentes de trabalho. São Paulo: Imprensa Oficial do Estado de São Paulo, 2010.

[12] NIOSH. Prevention through Design. Centers of Disease Control and Prevention. Disponível em: $<$ http://www.cdc.gov/niosh/topics/ptd/>. Acesso em: 01 mar. 2012.

[13] OCCUPATIONAL HEALTH AND SAFETY MANAGEMENT SYSTEMS - REQUIREMENTS - 12 OHSAS 18001:2007. Disponível em: < www.isotec-quality.com.br/normas/ohsas 18001.pdf>. Acesso em: 24 fev. 2012.

[14] OLIVEIRA, O. Gestão do processo de projeto na construção de edifícios. Integração, n. 38, p. 201217, jul./ago./set. 2004.

[15] SZYMBERSKI, R. T. Construction Project Safety Planning. TAPPI Journal, v. 80, n. 11, p. 6074, 1997.
[16] TOOLE, T.; GAMBATESE, J. The Trajectories of Prevention through Design in Construction. Journal of Safety Research, n. 39, p. 225-230, 2008. ISSN 0022-4375.

[17] VASCONCELOS, B. Segurança do trabalho no projeto de arquitetura: diretrizes para o controle dos riscos de acidente na fase pós-obra. 2009. 121 p. Dissertação (Mestrado em Construção civil) Escola Politécnica da Universidade de Pernambuco, Recife, 2009.

[18] VASCONCELOS, B.; SOEIRO, A.; BARKÓKEBAS, B. Prevention through Design: Guidelines for designers. Second European Conference on Health and Safety Coordination in the Construction Industry, 2011a.

. O Processo de Elaboração do Projeto de Estrututaras no Projecto de Estruturas e a Segurança no Trabalho - The Structural design process and the Safety at Work. $\mathbf{2}^{\mathbf{0}}$ Fórum Internacional de Gestão da Construção - GESCON 2011: Sistemas de Informação na Construção. Porto: Universidade do Porto, 2011b. CD-ROM. 